\title{
Representation of Youth Generation in the Mobile Phone and Internet Media in Sri Lanka
}

\author{
Manoj Jinadasa \\ University of Kelaniya, Sri Lanka
}

\begin{abstract}
This study explores the differences in behavioral patterns in youth generation that is affected by mobile phones and internet in Sri Lanka. Yet, culture and society of Sri Lanka has profoundly rooted by its traditional religious cultures, their behaviors have been shifted into a different phase as a result of the enormous usage of mobile phone and internet media. Penetration of mobile phone is substantially high (101\%), which is bigger with other developing countries in South-Asia from the very beginning in 2012. The use of internet is also gradually being increased comparing with other developing countries in South-Asia. Recent statistical reports reveal that nearly $21.9 \%$ of total population use internet in their daily use (2013). In this study, from 2011 up to 2015, rural and urban societies were explored using random sampling. This study conducted in mixed approach, as quantitative; survey (100 questionnaires) and qualitative; 20 in-depth interviews and participatory observation in some of the places where youth were highly assembled for their socio-cultural functions. Sri Lankan youth have sharply been changed in their behaviors by the new media culture. Youth's behaviors are inter-relationship, sexuality, learning modes and behaviors, socialization, taste of entertainment, imagination of aesthetic creativity, attitudinal development, use of information, social systems and life values have been dramatically changed by gradual development of the use of new media tools and equipment. Key social issue in youth in this is the lack of critical understanding. However, this study suggests a need of critical and innovative knowledge in use of mobile phone and internet so that they are enabling with use them for their personal and professional developmental purposes.
\end{abstract}

Keywords: representation, youth generation, mobile phone, internet, behavior

\section{Background}

In Sri Lanka, covering a large diversity of ethnic and cultural patterns, media circulation has rapidly expanded over the country with nearly sixty (60) Radio channels, fourteen (40) television channels and more than 60 printed media including newspapers, periodicals, and journals in all three languages of Sinhala, Tamil and English. Currently, Sri Lanka shows the highest penetration of mobile phone in developing countries in South-Asia (101\%). There is a tendency in the growth of use and circulation of internet.

Total population of Sri Lanka has reached to a maximum of 20,277,597 as at March, 2012 in terms of the preliminary report prepared by the department of Census and Statistics of Sri Lanka (preliminary report (provisional) - 1,2012 ). Population growth is 0.7 . Maximum of population represents by rural sector is $72.2 \%$, while urban sector is $21.5 \%$ and state sector is $6.3 \%$ (2011). Growth of GDP is $8.3 \%$ by 2011 as presented in Economic and Social Statistics of Sri Lanka-2012 (Central Bank of Sri Lanka, 2012:01).

Manoj Jinadasa, MSSc., Senior Lecturer in Mass Communication, Department of Mass Communication, University of Kelaniya. 
In the expansion of telecommunication as presented in above report, number of the wire-line telephone is 941,781 and the number of the cellular phones is $18,319,447$. Number of wireless telephone loop is $2,666,612$. Telephone density (telephones for 1,000 persons, including cellular phones) is 1,051. Number of the Internet and email subscribers is 844,000 billion (Central Bank of Sri Lanka, 2012:08).

On the other hand, there is a clear picture provided by the statistical report-2012 March of telecommunication regulatory board of Sri Lanka.

Table 1

Statistical Overview of the Telecommunication Sector as at End of 2012

\begin{tabular}{|l|c|}
\hline Number of System Licenses & 64 \\
\hline Total number of Fixed phones & $3,616,411$ \\
\hline Teledensity (Fixed Phones per 100 inhabitants) & $17.5^{*}$ \\
\hline Number of Cellular Mobile Subscribers & $18,866,134$ \\
\hline Mobile Subscription per 100 people & $91.3^{*}$ \\
\hline Internet \& Email Subscribers -Fixed & $375,000^{*}$ \\
\hline M Internet \& Email Subscribers (Mobile ) & $711,000^{*}$ \\
\hline Number of Public Pay Phone Booths & 6145 \\
\hline Trunk Mobile Radio Subscribers & $206^{*}$ \\
\hline
\end{tabular}

Note. ${ }^{*}$ Provisional.

In reference to these statistics and surveys in Table 1, it is apparently clear that the high growth in both internet and mobile phone including other related technologies of new media is possible with contemporary society of Sri Lanka.

As Figure 1 shows, from 1990 to 2012, there is a growing increase in the use of fixed access telephone in Sri Lanka, while from 2005 to 2008, it shows a considerable steep up. However, at the end of March 2012, when it comes to the provincial distribution of fixed telephone, Figure 2 indicates a significant difference between western province $(40 \%)$ and other provinces in the use of fixed access telephone.

Moreover, for years some efforts have been taken to develop high speed of broadband internet by TRC (Telecommunication regulatory Board). Some of the telecommunication cooperation like Dialog, SLT, Lanka bell and Suntel have been modified to gain sufficient speed in the broadband internet facility under certain issues immerged in geographical and technological sectors. From 2015, government has been taking some efforts to bring internet to the entire country using Google balloon.

Along with this, some studies and pilot tests are conducting currently in mounting internet protocol version-04 (IPV4) into internet protocol version-06 (IPV6) in Sri Lanka. Steps have been taking to enhance the quality of the internet and new media technology, so that its fundamental objective is to cater with national development.

But the mismatch comes with the quality of human life in their social and cultural life with the circulation of the forms of new media. It is understood that the lessons are inadequate to use the new forms of media, yet there is growing development of the tools of internet based communications (Jinadasa, 2006; 2008). In this, my attention has drawn to the cultural behaviors of youth generation which has been dramatically changed by the network society. In other words, even there is a substantial growth and utility of mobile phone with the internet, it is obscure why that of media use is impossible in advancing human quality that leads to improve national development leading to youth generation. 


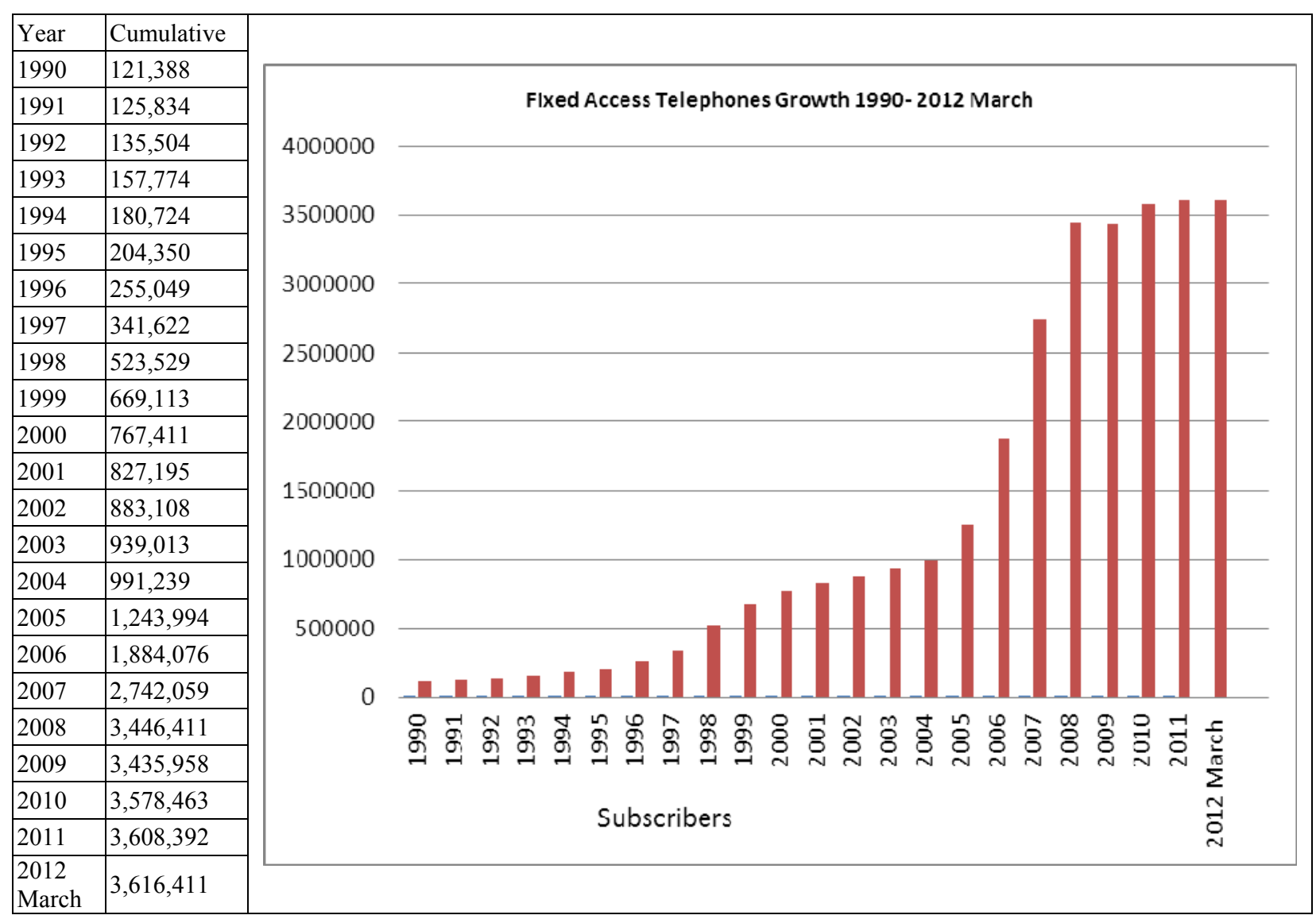

Figure 1. Performance of fixed access telephone operators.

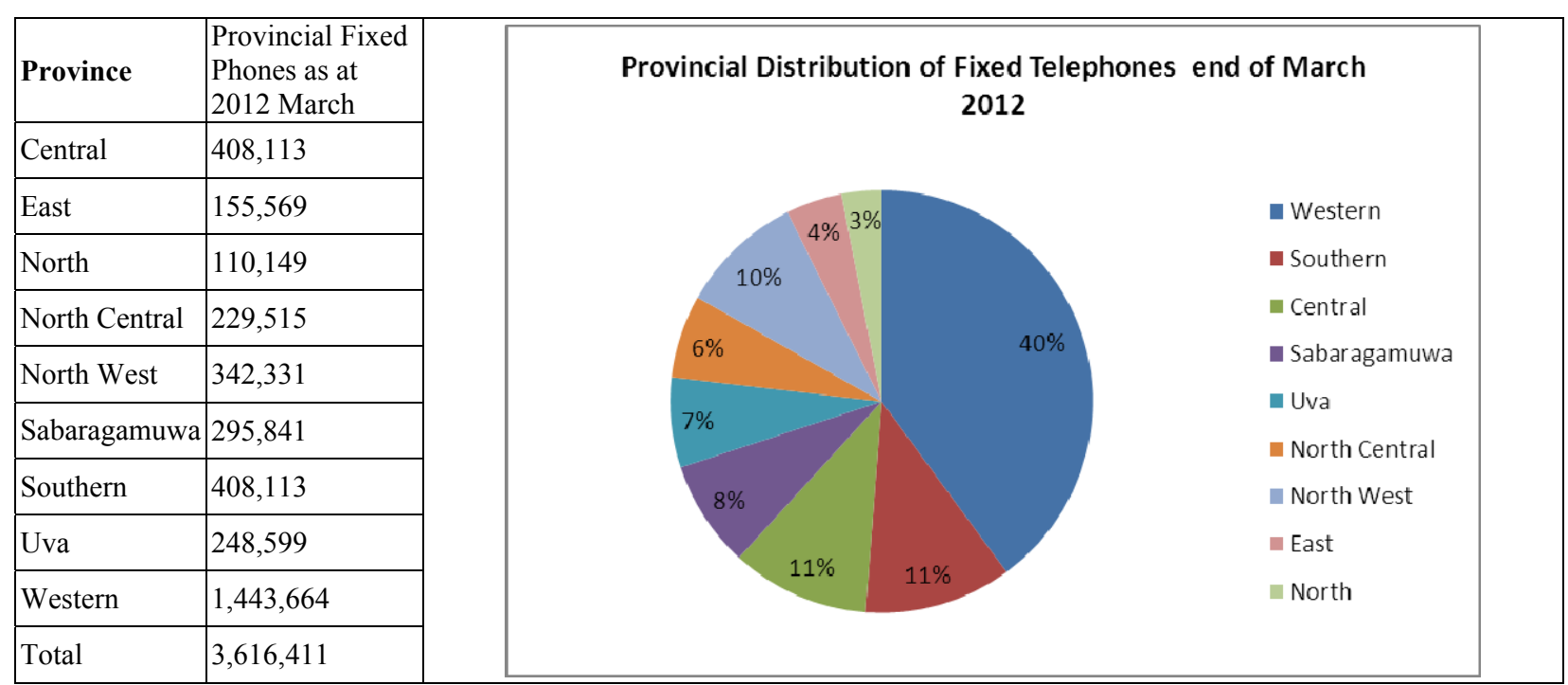

Figure 2. Performance distribution of fixed access telephone operators.

Fundamentally, for many years, there is a continuous dialogue and emphasis in the use and necessity of IT (Information Technology), Internet, and Mobile phone in the capacity to develop national education, health, cultural values and other planning in social development. At present, this is highly demanding as Sri Lanka is one of the middle range developing countries in the world. 
One of the possible reasons for this nature is even we have an immense growth in internet and mobile phone; we are inefficient in implementation them in the capacity of social development as new media technology and tools are not being properly taught by the education system. This has been correct in the current social incidents such as decreasing in the quality and standard of the national education which is unfit for handling existing local issues. Rate of crime and sexual harassments related to new media, wrongly interpreted political interference through social media which cause to destruct the pillars of democracy are some of the important changes in this venture. This situation signifies the overall massive collapse in culture and politics as the circulation of new media injecting new forms of cultural sophistications into the youth in Sri Lanka.

Extreme use of mobile phone and internet in network society in digital age for many needs and wants has been the fact in shaping and reshaping teen cultures (Castells, 2004; 2009; 2010). However, when it comes to the behavioral changes with this new media, specially teen and youth cultures are plugged in the rate of crime (Jinadasa, 2015) and sexual liberation that dance with their implicit clandestine relations (Jinadasa, 2015; 2010).

\section{Methodology}

This study conducted using mixed approach. Rural and urban societies were studied using convenient sampling. For the data gathering, Quantitative and qualitative methods as survey (100 questionnaires), 20 in-depth interviews and participatory observation in some places where youth was highly gathered for their socio-cultural functions were utilized.

For this sample, districts of Colombo, Kandy, Galle, Anuradhapura, and Kurunagala were used for selecting urban population. Districts of Ampara, Monaragala, Rathnapura, Jaffna, and Batticlaw were used for selecting rural population. 100 questionnaires were comprised by ten questionnaires from each district. Answer rate of this sample was $87 \%$.

For the qualitative analysis, 20 in-depth interviews were conducted from the districts by representing two subjects from each district. Participatory Observation was also used to justify some of the gathered data from interviews and questionnaires.

\section{Data Analysis}

All the subjects use mobile phone by $100 \%$, while some of them having extra phone for their interpersonal communication with others for clandestine relationships. And use of internet is not familiar like the use of mobile phone is only $58 \%$. This amount is largely represented by the rural and mid-urban sectors.

The use of mobile phone has shown diverse interests and needs. Primarily, it was used for interpersonal communication. In this, it is highlighted some of them use extra phone for covert relations specially leading to sexual bahaviors. Love affairs among teens have been dramatically changed into an intolerable type of affections, so that they are possible with releasing their instant feeling to one another from which it could be a disastrous for their life.

In the use of internet, a large number of subjects use it as a mode of entertainment rather than a form of educational mode is $95 \%$. Use of the Internet as a medium of entertainment is narrowed down for only listening songs, watching new movies, chatting and more on social media dialogues. Face book is the major and most commonly use social media in youth societies. Internet has been used as a motivation of sex instincts in many ways such as chatting, using internet camera, blogging, social media, and particularly the use of internet pornography. 
There is an increasing expansion of Compact Disk (CD) pornography prepared by the source of internet pornography as a big business among the teens and youth. This is highly being leaked into rural areas through the urban sectors. In addition, there are some places called internet cafes, specially made for the pornography over rural community in youth and teen. This is much ingrained in school children and university undergraduates. Type of Compact Disk (CD) pornography has created other cases in marital sexual relationships.

One of the resent case revealed from district of Monaragala far remote area in Sri Lanka is very important for this study. Her husband having seen a sexual intercourse of long duration in $\mathrm{CD}$, he has many times quarreled with his spouse and finally in the face of her inability of such a long course of sex she climbed to a jack tree for the protection from her husband and fallen down with severe back damage.

And several other interesting cases have been found in the expansion of homosexuality in remote and urban areas as an impact of CD circulation which emanated from internet sex clips and video movies. This has more peculiar in Ampara and Rathnapura as far remote rural areas and Colombo and Kandy as urban areas in Sri Lanka in the same manner. In addition, there is a dramatic change in school and teen cultures more particularly in urban and very popular collages, in organizing homosexual groups as an adopted cultural behavior created on the increase of internet and mobile phone. In this, it is something an extreme imitation of being westernization by receiving their sexual relationship in the bless of internet and mobile phone.

Moreover, it is seen such a big expansion of same sex, especially in gay in both urban and rural areas in Sri Lanka as an impact of internet via the mobile phone (Jinadasa, 2015). In this, social media is innovatively being utilized for the sexuality, interestingly among youth and teen cultures.

Even such a big expansion in internet, youth is not interested in using it for their educational events. In school level education, it is highly minimal in the use of internet as a form of informal mode of education; while in undergraduates' use, it is not for thorough awareness but for the preparation of their course assignments using only for copy and paste style. No critical and creative writing in their studies. Many youth engage in e-mail, blogging and social media for their interrelations of personal affairs (Ziththrin, 2008; Wittcower, 2010). They do not use it for searching new knowledge and professional development. However, there is a minimal use of social media for advertising their image and retaining their market of some of the teen members such as commercial models, actors, businessmen.

In a holistic perspective, the technology of both the tools of mobile phone and internet has not sufficiently spread out in rural sectors while some expansion is in the areas of urban. One of the reasons behind this is as the subjects see it is the lack of IT education in rural schools in Sri Lanka. Eighty-four percent (84\%) schools in Sri Lanka have no at least single computer in their education. However, there is a growing development in the use of smart phone in the youth generations as a result of the presentation new brands attractively in the popular markets.

New generation of youth and teen is much confident with consuming the latest version of highly expensive mobile phones at any price (Winston, 2003; Katz, 2008). In general, they used to change their phones with the introduction of new versions of the same. But they do no change their awareness or rationality with the grasping of latest mode of technology. They do not use it for their critical knowledge. And with this rapid circulation of mobile phone, there is no such a rapid growth in productivity in their daily works or studies. This is very peculiar among in the societies of adults. Consequently, the use of mobile phone also, has been a part and parcel of high consumerism prevailed in contemporary society in Sri Lanka as a result of capital economy. 


\section{Conclusions and Recommendations}

There is a considerable difference in the use of mobile phone and internet in the youth society in Sri Lanka. While it takes an expansion of new media, there is a considerable destruction of youth society behaviors in Sri Lanka. New media literacy is law irrespective of the high rate of language literacy in Sri Lanka. Concerning the studies of new media in the curricula of Mass communication, albeit some inclusion of new media for curricula, it is not sufficient with the rapid expansion of the use of mobile phone and internet with its tremendous socio-cultural issues. Thus, psychological and Philosophical analysis into the use of new media remains much applicability to this situation.

Rate of crime and murder has been increased with the circulation of the forms of new media is also significant in the new media society in Sri Lanka. Rate of divorce is also increasing dramatically by 40 to 50 cases as reported monthly in district courts. It is noteworthy to recommend for a thorough study of the relevance and relation of the rate of divorce and the use of new media. Many clandestine relations, that happens in the mobile phone has been the fact for such immediate divorce cases soon after their marriage.

Despite the fact that, having an immense understanding on the necessity of IT and new technology in communication, most updated versions of the communication technology of new media are being slowly adopted by the local audiences.

Two of the major misuses in the use of new media in youth are high interference of politics and malpractice in traditional media of TV, Radio and newspaper. The high consumer behavior and modern social competition that were engulfed to the Sri Lankan society have been interrelated with the misuse of new media within the generation of youth.

Education system is still in the course of traditional norms and policies of teaching and learning. However, some of the higher education institutions have been trying to adopt new electronic systems of education such as e-learning and online education system (LMS) refers with open, external and distance modes of education.

One of the crucial reasons behind the misuse of new media in the youth generation is the inadequacy of the learning in philosophy and aesthetic of human sciences of the use of new media. It is urgent to concern on the ethics and morals of human culture under the curricula of education, when there is a high exercise and growth of new communication technologies that transform world into efficient in the digital age. In the education system of Sri Lanka, nevertheless it is fundamentally emphasized the relevance and the importance of philosophy and psychology of the process of human mechanism, it has been decreased by the face of competition and extreme consumerism in modern capital economy.

In brief, New media has not relevantly been used for the critical understanding, so that the traditional interpretation for the concepts like democracy, human rights, rule of law, good governance, ethics and aesthetics, have been in both great sophistication and no of their pragmatic sense in the third world countries after the colonial period. Lack of innovative interpretation and critical understanding have been two factors that needs to project on the increase of high circulation of internet and mobile phone in Sri Lanka.

With this deficiency of critical knowledge in new media, it is crucially important to search for a new policy and regulation to govern the practice and use of the new media for decreasing their ill-effects towards youth generation.

\section{References}

Castells, M. (2004). The network society: A cross-cultural perspective. Cheltenham, UK: Edward Elgar. 
Castells, M. (2010). The information age: Economy, society and culture (Volume-1: The rise of the network society). Chichster, UK: Wiley Blackwell, A John Wiley \& Sons Ltd..

Castells, M. (2010). The information age: Economy, society and culture (Volume-11: The power of identity). Chichster, UK: Wiley Blackwell, A John Wiley \& Sons Ltd..

Castells, M. (2010). The information age: Economy, society and culture (Volume-111: The end of millennium). Chichster, UK: Wiley Blackwell, A John Wiley \& Sons Ltd..

Castells, M. (2009). Communication power. New York, USA: Oxford University Press.

Central Bank of Sri Lanka. (2012). Economic and social statistics of Sri Lanka-2012. Retrieved August 15, 2012, from from http://www.cbsl.gov.lk/pics_n_docs/10_pub/_docs/statistics/other/econ_\&_ss_2012.pdf

Jinadasa, M. (2015). Rate of crime and the involvement of army soldiers in Post Conflict Society in Sri Lanka: Gender representation in crime and lack of the psycho-social awareness in the army profession. Review of Journalism and Mass Communication, 3(2), 41-57. USA: American Research Institute for Policy Development.

Jinadasa, M. (2015). Internet through mobile phone and its cognitive and behavioral impact: Changing sexuality. Journalism and Mass Communication, 5(12), 614-628. doi: 10.17265/2160-6579/2015.12.002

Jinadasa, W. W. M. P. K. (2015). Community development programmes and folk-media: A communication model For Sri Lankan Rural Society. Global Media Journal-Indian Edition, 2(2).

Jinadasa, M. P. K. (2010). The difference of concepts of the societies of pre-media and post-media: Absence of a moral and ethical justice in sexuality in online media society. Proceedings of IPRC International Postgraduate Research Conference-2015: Emerging Concepts in Multidisciplinary Research (p. 314), Faculty of Graduate Studies, University of Sri Kelaniya, Kelaniya, Sri Lanka.

Jinadasa, W. W. M. P. K. (2008). A study of the use of psychological theories and concepts for understanding the nature and impact of media and communication; Media psychological perspective. International Conference on Social Sciences, Sri Lanka, 18-20 July, 2008, Research Centre for Social Sciences, Faculty of Social Sciences, University of Kelaniya, Kelaniya, Sri Lanka.

Jinadasa, W. W. M. P. K. (2010). The impact of media on abnormal sexual behaviors. Research Symposium 2010, Faculty of Graduate Studies, University of Kelaniya.

Jinadasa, W. W. M. P. K. (2015). Teen culture: A production of modern popular television and new media texts. Peradeniya University International Research Sessions-2015. Proceedings of iPURSE, Volume 19, p. 40, Faculty of Engineering, University of Peradeniya, Peradeniya, Sri Lanka.

Jinadasa, M. P. K., \& Rajapaksha, M. K. C. (2006). A study on the multidisciplinary nature of mass communication research dimensions: Modeling the issues and challenges towards sustainable development? 2nd International Symposium, July 8th-12th, 2008, Sabaragamuwa University of Sri Lanka, Kelaniya, Sri Lanka.

Katz, J. E. (Ed.). (2008). Hand book of mobile communication studies. Cambridge, Massachusetts: The MIT Press.

Telecommunications Regulatory Commission of Sri Lanka. (2012). Statistics. Retrieved July 5th, 2012, from http://www.trc.gov.lk/information/statistics.html

Wikipedia: The free encyclopedia. (2012). Media of Sri Lanka. Retrieved July 23, 2012, from http://en.wikipedia.org/wiki/Media_of_Sri_Lanka

Winston, B. (2003). Media technology and society: A history: From telegraph to the Internet. London, Routledge.

Wittcower, D. E. (2010). Facebook and philosophy. Illinois: Open Court, Chicago and La Salle.

Ziththrin, J. (2008). The future of the internet and how to stop it. New Haven: Yale University Press. 